\title{
Chronic kidney disease and poor outcomes in ischemic stroke: is impaired cerebral autoregulation the missing link?
}

\author{
Pedro Castro ${ }^{1 *}$ (D) Elsa Azevedo ${ }^{1}$, Isabel Rocha ${ }^{2}$, Farzaneh Sorond ${ }^{3}$ and Jorge M. Serrador ${ }^{4,5,6}$
}

\begin{abstract}
Background: Chronic kidney disease increases stroke incidence and severity but the mechanisms behind this cerebrorenal interaction are mostly unexplored. Since both vascular beds share similar features, microvascular dysfunction could be the possible missing link. Therefore, we examined the relationship between renal function and cerebral autoregulation in the early hours post ischemia and its impact on outcome.

Methods: We enrolled 46 ischemic strokes (middle cerebral artery). Dynamic cerebral autoregulation was assessed by transfer function (coherence, phase and gain) of spontaneous blood pressure oscillations to blood flow velocity within $6 \mathrm{~h}$ from symptom-onset. Estimated glomerular filtration rate (eGFR) was calculated. Hemorrhagic transformation (HT) and white matter lesions (WML) were collected from computed tomography performed at presentation and $24 \mathrm{~h}$. Outcome was evaluated with modified Rankin Scale at 3 months.

Results: High gain (less effective autoregulation) was correlated with lower eGFR irrespective of infarct side $(p<0.05)$. Both lower eGFR and higher gain correlated with WML grade $(p<0.05)$. Lower eGFR and increased gain, alone and in combination, progressively reduced the odds of a good functional outcome [ipsilateral $\mathrm{OR}=4.39$ (C195\% 3.15-25.6), $p=0$. 019; contralateral $\mathrm{OR}=8.15$ (Cl95\% 4.15-15.6), $p=0.002$ ] and increased risk of HT [ipsilateral $\mathrm{OR}=3.48$ (Cl95\% $0.60-24.0), p=0.132$; contralateral $\mathrm{OR}=6.43$ (Cl95\% 1.40-32.1), $p=0.034]$.

Conclusions: Lower renal function correlates with less effective dynamic cerebral autoregulation in acute ischemic stroke, both predicting a bad outcome. The evaluation of serum biomarkers of renal dysfunction could have interest in the future for assessing cerebral microvascular risk and relationship with stroke complications.
\end{abstract}

Keywords: Cardiovascular disease, Chronic kidney disease, Glomerular filtration rate, Stroke; transcranial Doppler

\section{Background}

Chronic kidney disease (CKD) increases the risk of ischemic stroke $[1,2]$, its severity and the chance of poor outcome $[3,4]$. The exact mechanisms that govern this cerebro-renal interaction are poorly understood [5]. A possible explanation may involve the similar features of kidney and brain microvascular beds. Both vascular beds are low resistance arterial beds that rely on continuous blood flow that ismaintained at relatively constant levels by a fine-tuned myogenic regulatory system. This confers protection to both the brain and kidney from arterial

\footnotetext{
* Correspondence: pedromacc@gmail.com

'Department Neurology, São João Hospital Center, Faculty of Medicine of University of Porto, Alameda Professor Hernani Monteiro, 4200-319 Porto, Portugal

Full list of author information is available at the end of the article
}

blood pressure $(\mathrm{ABP})$ fluctuations that could cause large swings in blood flow [6-8]. This property, called autoregulation, has been long known to exist in renal [9] and cerebral $[10,11]$ vasculatures. Despite differences between organ systems, autoregulation is viewed as a generalized vascular protective mechanism [8] witch failure results in microvessel damage (e.g. from uncontrolled hypertension and diabetes [12-15]). In fact, glomerular sclerosis of chronic kidney failure [16], as well as lacunar infarcts and white matter lesions (WML) in the brain $[12,17]$, are all characterized by similar pathological conditions: endothelial dysfunction; ischaemic arteriosclerosis; low perfusion and small vessel leakage [12, 17]. Recent evidence shows that kidney impairment is associated with a greater severity of cerebral WML [18]. 
Because microvascular dysfunction impairs myogenic autoregulation, this could be the missing link between renal dysfunction and stroke morbidity and worthwhile of being explored. Dynamic cerebral autoregulation (CA) is rapidly and noninvasively assessed at the patient bedside by transfer function analysis (TFA) using spontaneous oscillations in ABP and cerebral blood flow velocity (CBFV) [14, 19-22] which is known to be impaired in acute ischemic stroke [23].

In this study, we examined the relationship between renal function and CA, assessed from TFA measured within $6 \mathrm{~h}$ of symptom-onset and its impact on longterm outcome.

\section{Methods}

\section{Population studied}

The study was conducted in Hospital Center São João, Porto, and its local ethical committee approved the study and all participants or proxy signed written informed consent. We included consecutive patients with acute ischemic stroke admitted to our stroke unit and with time from symptom onset, or from last seen well, within $6 \mathrm{~h}$. Most patients admitted after 8:00 p.m. or weekends were not enrolled because transcranial Doppler (TCD) monitoring was not available. Exclusion criteria included hemodynamic instability requiring vasoactive agents, other central neurological co-morbidities, acute renal injury [24] or insufficient temporal window. We recruited 46 patients with ischemic stroke in middle cerebral artery (MCA) territory. All participants underwent cervical and transcranial ultrasound studies (Vivid e; GE) before evaluation to exclude hemodynamically significant extra- $(>50 \%$ in carotid artery calculated by NASCET method) or intracranial stenosis ( $\geq$ $50 \%$ by angle-corrected velocimetric criteria). Blood samples were collected at admission. We calculated Estimated glomerular filtration rate (eGFR) using the Chronic Kidney Disease Epidemiology Collaboration formula [25-27]. In the first fasting sample, we obtained total, low-density lipoprotein (LDL) and high-density lipoprotein (HDL) cholesterol, glucose and glycated hemoglobin (HgA1C).

\section{Clinical assessment}

All patients underwent a neurological examination at presentation and National Institute of Health Stroke Scale (NIHSS) scores were calculated at baseline. The outcome, assessed by clinical interview, corresponded to mortality and functional independence [modified Rankin Scale (mRS) 0-2] at 90 days.

\section{Monitoring protocol}

Evaluations were carried out in the stroke unit with the head of the bed at $0^{\circ}$. ABP was continuously monitored with a finger cuff in the unaffected side using Finometer MIDI (FMS, Amsterdam, Netherlands). Additionally, ABP was assessed with oscillometric cuff (Dash 2500, GE, UK). Heart rate was assessed from lead II of a standard 3-lead electrocardiogram. CBFV was recorded bilaterally from M1 segment of MCA (depth of 50-55 mm) with 2-MHz monitoring probes secured with a headband (Doppler BoxX, DWL, Singen, Germany). End-tidal carbon dioxide was evaluated by nasal cannula attached to Respsense capnograph (Nonin, Amsterdam, The Netherlands). All data was synchronized at $400 \mathrm{~Hz}$ with Powerlab (AD Instruments, Oxford, UK) and stored for offline analysis. Data collection occurred for $10 \mathrm{~min}$ within $6 \mathrm{~h}$ from symptoms-onset.

\section{Cerebral autoregulation data analysis}

All signals were inspected using a custom based Matlab ${ }^{\circ}$ program and artifacts removed by linear interpolation [28]. Systolic, mean and diastolic values of ABP and CBFV were calculated. For each heart-beat estimated cerebrovascular resistance (CVRi) was calculated by mean ABP/ CBFV, reflecting vasomotor function [29]. TFA was used to assess dynamic CA by calculating coherence, gain and phase parameters from $10 \mathrm{~min}$ of beat-to-beat spontaneous oscillations of CBFV and $\mathrm{ABP}$ as previously reported $[26,27,30,31]$. Coherence, gain and phase are reported for the low-frequency range (LF: $0.03-0.15 \mathrm{~Hz}$ ), which is the autoregulatory frequency $[6,20,21,30]$, and also at high-frequency (HF: $0.15-0.5 \mathrm{~Hz}$ ) band. In short, coherence is the coefficient of correlation between the signals; higher coherence between the oscillations is reflective of less effective CA. Gain quantifies the damping effect of $\mathrm{CA}$ on the magnitude of ABP oscillations. Phase shift represents the time delay between $\mathrm{ABP}$ and CBFV oscillations. Lower gain and higher phase represent tighter, more effective autoregulatory response [20].

\section{Neuroimaging assessment}

Computed Tomography brain scan (Siemens Somaton Emotion Duo, Erlangen, Germany), with 3 to $6 \mathrm{~mm}$ slices, was performed at presentation and repeated at $24 \mathrm{~h}$. Hemorrhagic transformation was defined as any hemorrhage ranging from petechial hyperdensities to parenchymal hematoma [32]. WML, a correlate of cerebral microvascular disease, [17] were graded by the van Swieten [33] scale based on the first scan, a method validated against MRI in ischemic stroke [34].

\section{Statistical analysis}

Normality was determined by Shapiro-Wilk test. Baseline data are presented for all subjects. The relationship between baseline characteristics, including eGFR, and CA parameters were determined by multivariate and univariate linear regression analysis adjusting for age, gender and other significantly related variables at previous univariate analysis. To better depict the relationship between CA and eGFR, we divided the first by median and the latter into subgroups 
of low and high $\left(<60\right.$ and $\geq 60 \mathrm{~mL} / \mathrm{min} / 1.73 \mathrm{~m}^{2}$, respectively) subgroups. Any subgroups were compared with Kruskal-Wallis and Mann-Whitney tests. The impact of eGFR on the outcome (mRS 0-6) and association with WML grades (0-4) were characterized by ordinal regression analysis. The risk of hemorrhagic transformation was assessed by logistic regression analysis. To avoid spurious associations, we considered statistically significant at $P<0.01$ level for univariate regression analysis. Otherwise, $P<0.05$ cut-off was used. All statistics were performed using IBM Statistical Package for Social Sciences (SPSS) Statistics v21 ${ }^{\mathrm{Tx}}$.

\section{Results}

\section{Renal function and cerebral autoregulation}

Baseline characteristics and hemodynamic data are reported in Tables 1 and 2, respectively. In a multivariate linear regression analysis, greater LF and HF gain values (indicating less effective $\mathrm{CA}$ ) within $6 \mathrm{~h}$ of symptoms were significantly associated with lower eGFR irrespective of infarct side $(p<0.05$, Table 3$)$. Phase and coherence were not related to any baseline variable. Additional file 1: Table S4 shows the results of univariate linear regression. Figure 1 shows the distribution of CA parameters throughout all spectrum of frequencies. We found significantly higher gain values in low eGFR subgroup compared to the high one $(p<0.05)$.

Previous use of Calcium Channel Blockers (CCB) was associated with higher gain values bilaterally $(p<0.05$, Table 3). To explore further the influence of chronic medication with $\mathrm{CCB}$ we compared gain values in those using CCB $(n=10)$ compared to patients who were not on CCB (Fig. 2a and b) as well as renal function (Fig. 2c). CCB use was associated with higher gain values $(p<0.05)$ and also lower eGFR (57 and $75 \mathrm{ml} / \mathrm{min}, p=0.022$ ) but this was not statistically significant if we only compared chronically hypertensive patients $(N=37,57$ and $70 \mathrm{ml} / \mathrm{min}, p=$ 0.082). ABP at presentation was not different between those on CCB compared to those not on CCB (systolic $137 \pm 21$ vs $138 \pm 20 \mathrm{mmHg}, p=0.901$; diastolic $47 \pm 12$ vs $55 \pm$ $14 \mathrm{mmHg}, p=0.125$ ).

\section{Relationship with cerebral microvascular disease (WML)}

WML severity was correlated in an inverse manner with lower levels of eGFR (rho Spearman $=-0.52, p<0.0001$ ) and proportionally to higher levels of LF gain (ipsilateral $r=0.368, p=0.040$; contralateral $r=0.402, p=0.006$ ). This can be depicted clearly in figs. $3 \mathrm{c}$ and $4 \mathrm{c}+\mathrm{F}$, where we explored the distribution of WML grades accordingly to subgroups of low and high eGFR and LF gain, respectively. In Fig. $5 \mathrm{c}$ and $\mathrm{f}$, we demonstrate the interaction between renal function and dynamic CA, by studying subgroups of eGFR versus subgroups of LF gain. Lower eGFR and higher LF gain (worse CA) were associated with more
Table 1 Demographics and baseline characteristics of patients $(N=46)$

\begin{tabular}{ll}
\hline Demographics & \\
Male, $n$ (\%) & $19(41)$ \\
Age, years (mean \pm SD) & $73 \pm 12$ \\
BMI, Kg.m ${ }^{-2}$ (mean \pm SD) & $27 \pm 5$ \\
Previous stroke/TIA, $n(\%)$ & $6(13)$ \\
Hypertension, $n$ (\%) & $28(61)$ \\
Diabetes Mellitus, $n(\%)$ & $14(30)$ \\
Dyslipidemia, $n(\%)$ & $27(59)$ \\
Tobacco, $n(\%)$ & $4(9)$ \\
Previous MI, $n(\%)$ & $2(4)$ \\
Atrial Fibrillation, $n$ (\%) & $20(43)$ \\
Chronic Medication, $n$ (\%) & \\
Antiplatelet & $18(39)$ \\
Statin & $17(37)$ \\
Beta-Blocker & $10(22)$ \\
ACEl/ARB & $15(33)$ \\
CCB & $9(20)$
\end{tabular}

Stroke characteristics

Etiology (TOAST), n (\%)

Large Vessel

Cardioembolic

Small vessel

$2(4)$

Other

$1(2)$

Undetermined

$12(26)$

Occlusion of affected MCA

$16(35)$

Baseline NIHSS score [median(IQR)]

$14(9-22)$

Neuroimaging [median(IQR)]

Infarct Volume, $\mathrm{mL}$

19 (2-139)

Leucoencephalopathy grade (VanSwieten scale [33])

$2(1-3)$

Laboratorial (mean $\pm S D$ )

Total cholesterol, $\mathrm{mg} / \mathrm{dL}$

$174 \pm 72$

LDL cholesterol, $\mathrm{mg} / \mathrm{dL}$

$105 \pm 42$

HDL cholesterol, mg/dL

$46 \pm 11$

Triglycerides, $\mathrm{mg} / \mathrm{dL}$

$111 \pm 68$

Glucose, mg/dL

$140 \pm 81$

$\mathrm{HbA1C}$ \%

$6.4 \pm 1.4$

Creatinine, mg/dL

$1.0 \pm 1.0$

Renal Function

eGFR, $\mathrm{ml} / \mathrm{min} / 1.73 \mathrm{~m}^{2}$

$80 \pm 39$

CDK-EPI Stage 0-1, $\mathrm{n}(\%) \quad 10(22)$

CDK-EPI Stage 2, n (\%) $23(50)$

CDK-EPI Stage 3, n (\%) 13 (28)

CDK-EPI Stage $4, n(\%)$

CDK-EPI Stage $5, n(\%)$

1 (2)

Body-Mass Index $(B M I)$, Transitory Ischemic Attack (TIA), angiotensin-conversionenzyme inhibitor $(A C E)$, angiotensin receptor blocker (ARB), calcium channel blocker (CCB), Trial of ORG10172 in Acute Stroke Treatment (TOAST), middle cerebral artery (MCA), National Institutes of Health Stroke Scale (NIHSS), Low-density lipoprotein $(L D L)$, High-density lipoprotein $(L D L)$, glycated hemoglobin (HbA1C), eGFR (estimated glomerular filtration rate) by Chronic Kidney Disease Epidemiology Collaboration (CKDEPI) formula [25] 
Table 2 Systemic and cerebral hemodynamic characteristics of patients $(N=46)$

\begin{tabular}{|c|c|}
\hline \multicolumn{2}{|l|}{ Systemic hemodynamics (mean \pm SD) } \\
\hline Systolic ABP, mmHg & $144 \pm 19$ \\
\hline Mean $\mathrm{ABP}, \mathrm{mmHg}$ & $98 \pm 11$ \\
\hline Diastolic ABP, mmHg & $75 \pm 11$ \\
\hline Heart rate, bpm & $67 \pm 11$ \\
\hline LF mean ABP variability, $\mathrm{mmHg}^{2}$ & $85 \pm 111$ \\
\hline $\mathrm{HF}$ mean $\mathrm{ABP}$ variability, $\mathrm{mmHg}^{2}$ & $13 \pm 20$ \\
\hline $\mathrm{EtCO}_{2}, \mathrm{mmHg}$ & $36 \pm 7$ \\
\hline \multicolumn{2}{|l|}{ Cerebral hemodynamics (mean $\pm S D$ ) } \\
\hline \multicolumn{2}{|l|}{ |psilateral } \\
\hline $\mathrm{MFV}, \mathrm{cm} / \mathrm{s}$ & $40 \pm 20$ \\
\hline CVRi, $\mathrm{mmHg} /(\mathrm{cm} / \mathrm{s})$ & $2.3 \pm 0.9$ \\
\hline LF MFV variability, $(\mathrm{cm} / \mathrm{s})^{2}$ & $128 \pm 142$ \\
\hline HF MFV variability, $(\mathrm{cm} / \mathrm{s})^{2}$ & $35 \pm 49$ \\
\hline \multicolumn{2}{|l|}{ Contralateral } \\
\hline MFV, $\mathrm{cm} / \mathrm{s}$ & $48 \pm 17$ \\
\hline $\mathrm{CVRi}, \mathrm{mm} \mathrm{Hg} /(\mathrm{cm} / \mathrm{s})$ & $1.7 \pm 0.7$ \\
\hline LF MFV variability, $(\mathrm{cm} / \mathrm{s})^{2}$ & $200 \pm 250$ \\
\hline HF MFV variability, $(\mathrm{cm} / \mathrm{s})^{2}$ & $47 \pm 68$ \\
\hline \multicolumn{2}{|l|}{ Dynamic cerebral autoregulation } \\
\hline \multicolumn{2}{|l|}{ |psilateral } \\
\hline LF coherence, a.u. & $0.5 \pm 0.2$ \\
\hline LF gain, $\%^{2} / \mathrm{mmHg}^{2}$ & $1.0 \pm 0.3$ \\
\hline LF phase, degrees & $32 \pm 23$ \\
\hline HF coherence, a.u. & $0.6 \pm 0.2$ \\
\hline HF gain, $\%^{2} / \mathrm{mmHg}^{2}$ & $1.5 \pm 0.6$ \\
\hline HF phase, degrees & $-0.1 \pm 13$ \\
\hline \multicolumn{2}{|l|}{ Contralateral } \\
\hline LF coherence, a.u. & $0.5 \pm 0.2$ \\
\hline LF gain, $\%{ }^{2} / \mathrm{mmHg}^{2}$ & $1.2 \pm 0.5$ \\
\hline LF phase, degrees & $44 \pm 26$ \\
\hline HF coherence, a.u. & $0.7 \pm 0.2$ \\
\hline HF gain, $\%^{2} / \mathrm{mmHg}^{2}$ & $1.5 \pm 0.6$ \\
\hline HF phase, degrees & $-0.7 \pm 13$ \\
\hline
\end{tabular}

Arterial blood pressure $(A B P)$, mean flow velocity (MFV), estimated cerebrovascular resistance (CVRi), end-tidal carbon dioxide (EtCO2), Low (LF: $0.3-0.15 \mathrm{~Hz}$ ) and high (HF: $0.15-0.5 \mathrm{~Hz}$ ) frequency spectral bands; a.u., arbitrary units

severe white matter lesion grades (ordinal shift analysis of infarct side $p=0.045$ and non-infarct side $p=0.009$ ).

\section{Renal function, cerebral autoregulation and outcome}

As presented in Fig. 4a, lower GFR reduces significantly the odds of a good outcome (grade of 0-2) measured by mRS at 3 months [Fig. 3a, lower eGFR as reference, ordinal regression odds ratio, $\mathrm{OR}=0.32$ (confidence interval, $\mathrm{CI}$,
95\% 0.10-0.56), $p=0.005]$ and higher risk of hemorrhagic transformation [Fig. 3b, logistic regression OR 0.97 (CI95\% $0.95-0.99), p=0.026]$.

Figure 4 depicts outcome accordingly to CA status. Higher LF gain (worse CA) also increased the odds of a poor outcome $(\mathrm{mRS}>2)$ [Fig. 4a, ipsilateral $\mathrm{OR}=2.18$ (CI95\% 1.01-5.28), $p=0.048$; fig. $4 \mathrm{~d}$, contralateral $\mathrm{OR}=$ 2.17 (CI95\% 1.12-4.17), $p=0.022$ ], and the risk of developing hemorrhagic transformation [Fig. 4b, ipsilateral $\mathrm{OR}=1.98$ (CI95\% 1.002-8.12), Fig. 4e, $\mathrm{p}=0.042$; contralateral $\mathrm{OR}=2.79$ (CI95\% 1.03-7.56), $p=0.043$ ].

An ordinal regression model with interaction between decreasing eGFR and increasing LF gain (Fig. 5a and d) found that both factors combine to progressively reducing the odds of a good functional outcome [ipsilateral $\mathrm{OR}=4.39 \quad(\mathrm{CI} 95 \% 3.15-25.6), \quad p=0.019$; contralateral $\mathrm{OR}=8.15$ (CI95\% 4.15-15.6), $p=0.002$. Multinomial logistic regression also found an interaction between lower eGFR and higher LF gain with an increased risk of hemorrhagic transformation that was only statistically significant on the contralateral side [Fig. $5 \mathrm{~b}$ and e, ipsilateral $\mathrm{OR}=3.48(\mathrm{CI} 95 \% 0.60-24.0), p=0.132$; contralateral OR $=6.43(\mathrm{CI} 95 \% 1.40-32.1), p=0.034]$.

\section{Discussion}

Our data shows significant association between impaired cerebral autoregulation (higher dynamic CA gain values) assessed during acute ischemic stroke $(<6 \mathrm{~h})$ and impaired renal function (lower glomerular filtration rate) independent of age, vascular risk factors and relevant laboratory metabolic control parameters. Moreover, both impaired renal function and impaired cerebral autoregulation (i.e. high gain values) were associated with greater white matter abnormalities and with reduced likelihood of a good functional outcome (scale of 0-2) as assessed by mRS at 3 months.

To understand why impaired renal function might be linked to impaired cerebral autoregulation, we need to consider the physiology of autoregulation. Renal autoregulation adjusts vascular resistance to stabilize renal blood flow and filtration rate during changes in renal perfusion pressure [7]. Basically, as pressure changes stretch the smooth muscles of the afferent and cortical arterioles, a myogenic response occurs to adjust the vascular resistance to maintain flow. Since blood flow in a vascular bed is determined by perfusion pressure and resistance (Blood flow $=$ perfusion pressure/vascular resistance), if perfusion pressure increases, stretching the smooth muscle surrounding the arterioles, the arterioles will then constrict to increase resistance and maintain the ratio of pressure to resistance and thus maintain blood flow [7]. In fact, renal autoregulation status has been well documented by the same method of TFA we used to assess dynamic CA. This method quantifies the transfer of blood pressure 


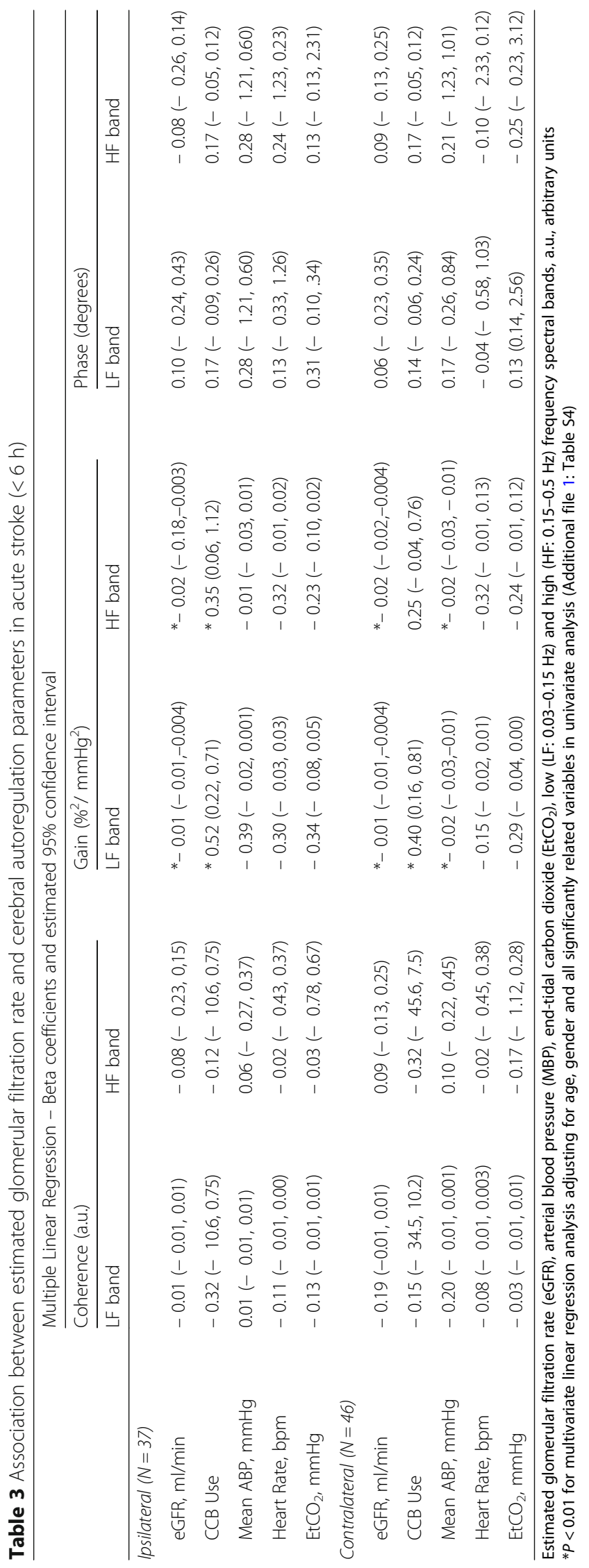


Infarct Hemisphere
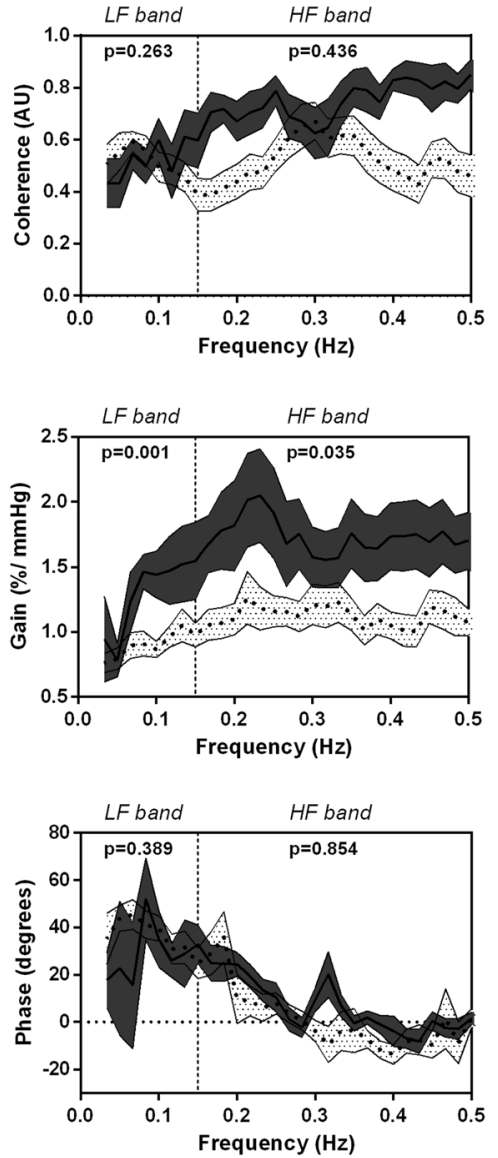

Non-infarct Hemisphere
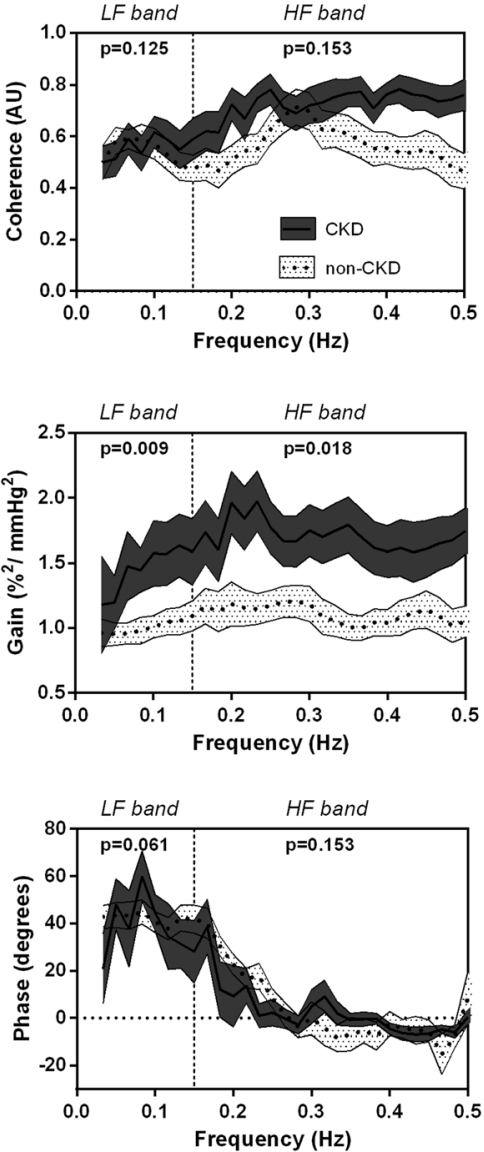

Fig. 1 Frequency spectra from 0.03 to $0.5 \mathrm{~Hz}$ of Coherence and Transfer Function Gain and Phase measured in acute stroke patients $(<6 \mathrm{~h})$ accordingly to their estimated glomerular filtration rate (eGFR). Continuous and spotted lines within dark grey and spotted white strips corresponds to means \pm SE of groups of low $\left(<60 \mathrm{~mL} / \mathrm{min} / 1.73 \mathrm{~m}^{2}\right)$ and high $\left(\geq 60 \mathrm{~mL} / \mathrm{min} / 1.73 \mathrm{~m}^{2}\right)$ subgroups of eGFR, respectively. Groups were compared with MannWhitney and $P$ values presented at right superior corner of each plot. Lower GFR shows higher gain values bilaterally which indicate less effective dynamic cerebral autoregulation

changes into flow change, thus high gain means that pressure changes are causing flow changes, and thus autoregulation is impaired. In the kidney, previous work in hypertensive rats with adenine-induced chronic renal failure has shown that gain is increased in the $<0.1 \mathrm{~Hz}$ band, suggesting higher gain is an indicator of impaired renal autoregulation [35].

The same characteristics are found in the cerebrovasculature with increased gain in the low-frequency range associated with impaired cerebral autoregulation [10, 20]. In fact, myogenic autoregulation is widely distributed over various vascular beds including the brain, coronary, pulmonary, mesenteric, and skeletal muscle [8].

Considering the similarities in the characteristics of autoregulation in the kidney and brain, one could propose that microvascular damage (e.g. caused by hypertension, diabetes) that causes impairment of kidney function $[7,16]$ could also affect the brain in a similar fashion.
Support for this idea is found in stroke-prone spontaneouslyhypertensive rats that have a genetic predisposition to rapid glomerulosclerosis and stroke [36]. In fact, in these rats, both renal autoregulation (assessed by TFA) and cerebral autoregulation are impaired prior to the development of stroke and death [37, 38]. Examination of the histopathology of cerebral arteries in the spontaneously hypertensive rats have also shown medial hypertrophy and remodeling, [39] that are hallmarks of small vessel disease, as in humans [17]. Thus it would appear that the stroke-prone spontaneously hypertensive rats show impairments of autoregulation in both the kidney and brain, prior to stroke. These data would suggest, in this animal model, that impairment of autoregulation is occurring in multiple vascular beds.

Taken together, this would suggest that if patients demonstrate less effective autoregulation in the cerebral vasculature (high gain) they would likely also have impaired renal 


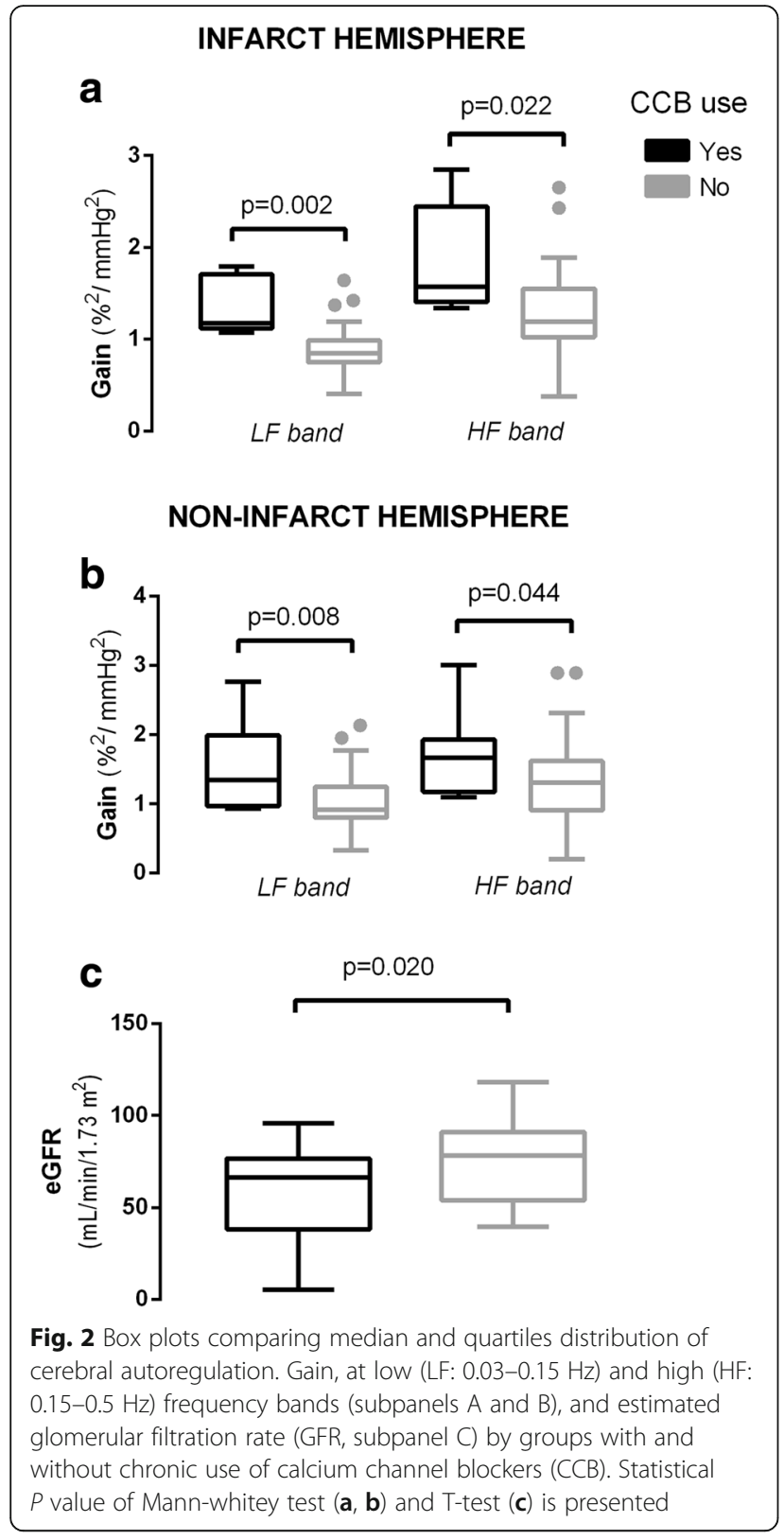

myogenic autoregulation, which would cause glomerular dysfunction.

One interesting finding was that previous CCB use was correlated to increased LF gain values in both cerebral hemispheres as well as reduced eGFR. A possible explanation for this finding lies in the effect of $\mathrm{CCB}$ on autoregulation. In fact, previous work has demonstrated that CCB impairs the myogenic response in the kidney in animal models $[7,40]$ and perhaps in humans $[41,42]$. CCB block the L-type voltage-gated calcium channels that are activated by the stretch of the arterial vessel wall [7]. Thus changes in pressure that result in changes in stretch of the walls will no longer activate the release of calcium and contraction of smooth muscle to modulate vascular

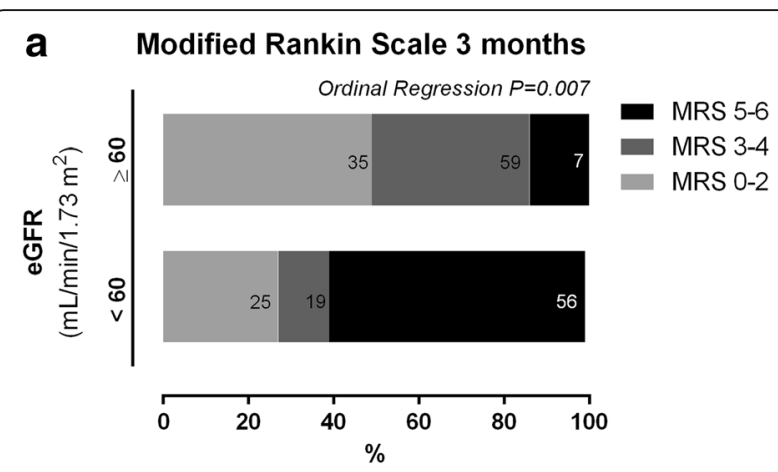

b Hemorrhagic Transformation

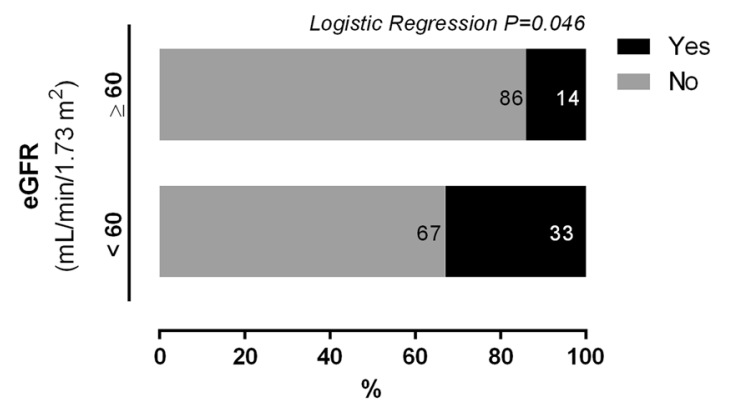

C White Matter Lesions Severity

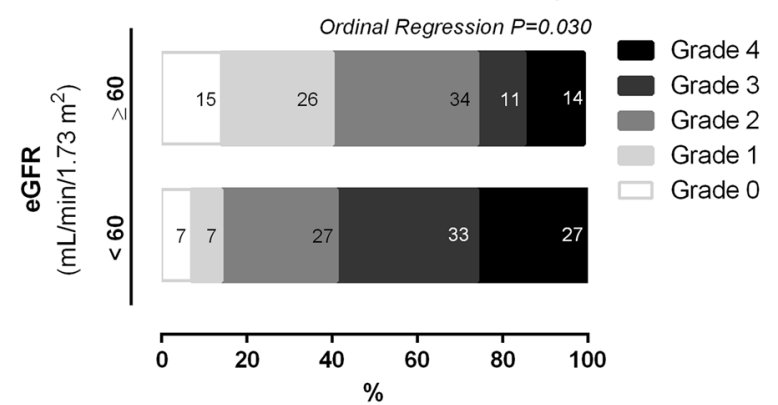

Fig. 3 Relationship between renal function subgroups of low $\left(<60 \mathrm{~mL} / \mathrm{min} / 1.73 \mathrm{~m}^{2}\right)$ and high $\left(\geq 60 \mathrm{~mL} / \mathrm{min} / 1.73 \mathrm{~m}^{2}\right)$ subgroups of estimated glomerular filtration rate (eGFR) and outcome accordingly to modified Rankin scale (a), risk of hemorrhage (b) and the severity of white matter lesions assessed at 24-h head Computed Tomography, accordingly to vanSwieten scale [33]. Subgroups were compared with ordinal regression or logistic regression as appropriate

resistance to maintain flow, which we would expect to result in an increased gain (i.e. worse autoregulation). The finding that $\mathrm{CCB}$ are associated with increased gain and poor eGFR may be due to CCB impairing autoregulation in both organs (brain and kidney), consistent with our hypothesis. However, the effect of CCB on cerebral autoregulation in humans is not as clear with studies, using measures other than TFA, showing impaired autoregulation, [41-43] while another study found no change in TFA derived gain in 8 healthy individuals [44].

Our finding that both low eGFR and high gain were significantly associated with severe WML grade does suggest that impaired autoregulation in the brain and kidney 
INFARCT HEMISPHERE

a Modified Rankin Scale 3 months

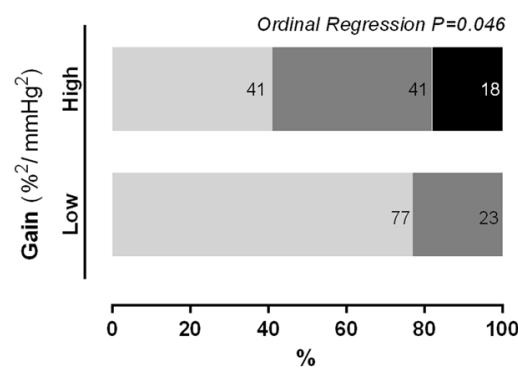

b Hemorrhagic Transformation

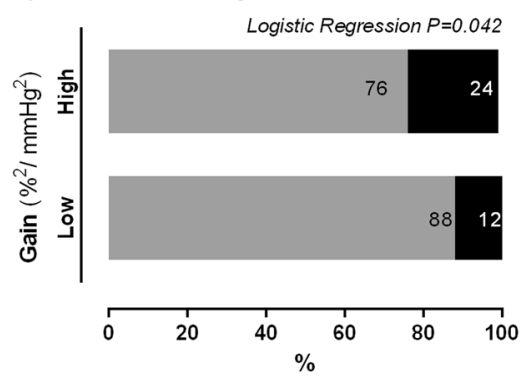

C White Matter Lesions Severity

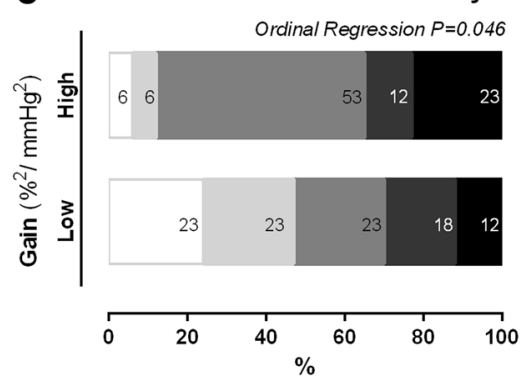

NON-INFARCT HEMISPHERE

d

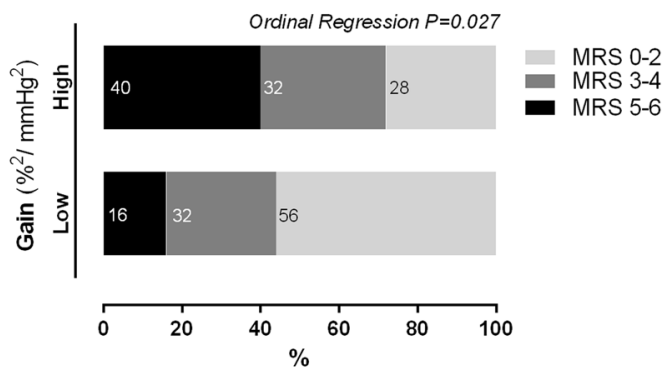

e

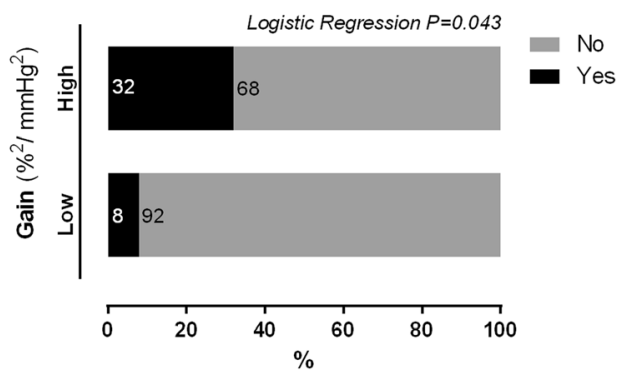

f

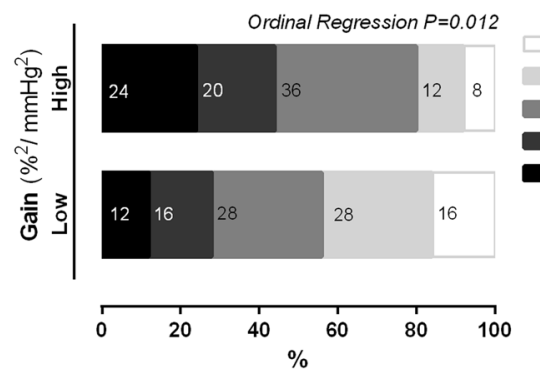

Fig. 4 Relationship between cerebral autoregulation within $6 \mathrm{~h}$ of symptoms by subgroups of low and high LF gain subgroups for infarct $\left(\leq 0.90,>0.9 \%{ }^{2} / \mathrm{mmHg}^{2}\right.$, respectively) and non-infarct hemisphere $\left(\leq 1.10,>1.10 \%{ }^{2} / \mathrm{mmHg}^{2}\right.$, respectively) and outcome accordingly to modified Rankin scale (a), risk of hemorrhage $(\mathbf{b})$ and the severity of white matter lesions assessed at 24-h head Computed Tomography, accordingly to vanSwieten scale [33]. Subgroups were compared with ordinal regression or logistic regression as appropriate

may be associated. A suggested mechanism for this is that microvascular damage is the basis of this autoregulatory dysfunction. Our work is the first to demonstrate that low eGFR is significantly associated with high gain and severe WML. From our data, we cannot rule out if WML cause cerebral autoregulation impairment or the opposite. Previous work has demonstrated that WML are correlated with cerebral autoregulation efficiency [14]. However, we hypothesize that both WML, as well as worse cerebral autoregulation, are expressions of a systemic microvascular dysfunction that can also impair renal function. Further prospective studies could untangle what's cause or consequence.

Another finding in our study was the relationship between high gain, low eGFR and hemorrhagic transformation. Higher gain values reflect less effectiveness in the dampening capability of cerebral resistance vessels in the insonated vascular territory to ABP oscillations [6]. These dysfunctional vessels disrupt Starling's principle by increasing the hydrostatic pressure across the capillary bed and contribute to the existing blood-brain barrier leakage [45]. Therefore, this might explain the association of higher gain and the risk of hemorrhagic transformation and cerebral edema [27]. Also, high gain values have been implicated in acute intracerebral hemorrhage [21, 46] and hematoma expansion [46].

In the infarcted hemisphere, gain had more nonsignificant relationships with outcome measurements. This can be observed by inspecting figs. 4 and 5 . One obvious explanation is that some patients had occluded MCA at infarct side and CA cannot be assessed at infarct side in the severe cases. Therefore, gain apparently 


\section{INFARCT HEMISPHERE}

a Modified Rankin Scale 3 months

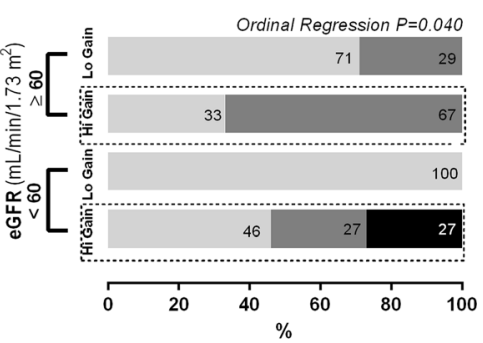

b Hemorrhagic Transformation

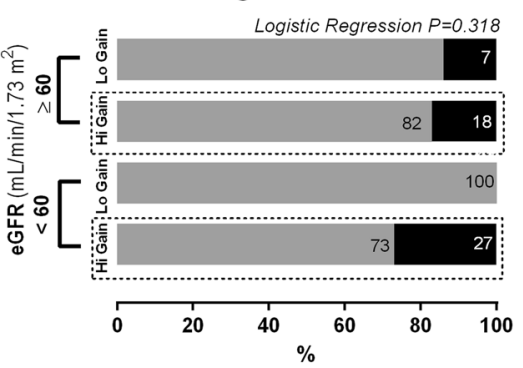

C White Matter Lesions Severity

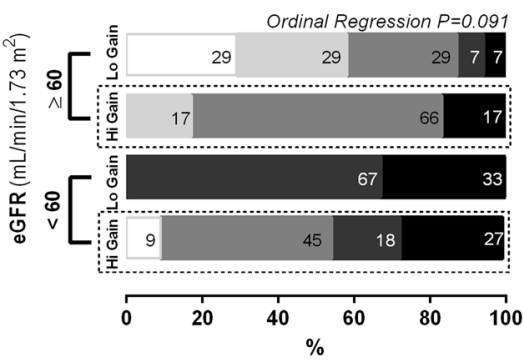

NON-INFARCT HEMISPHERE

d

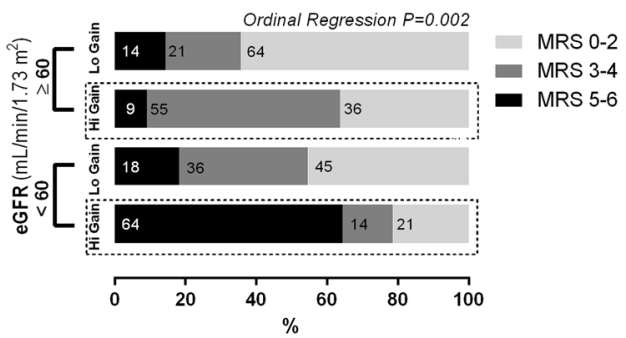

e

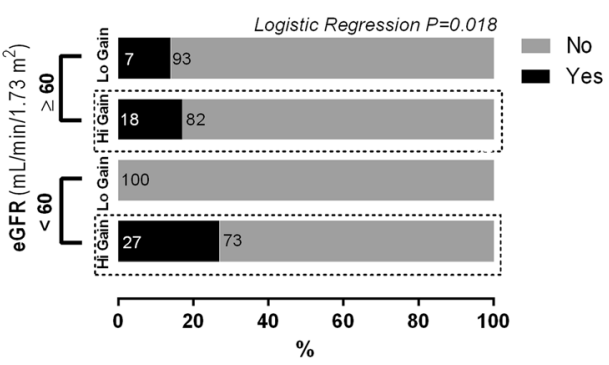

f

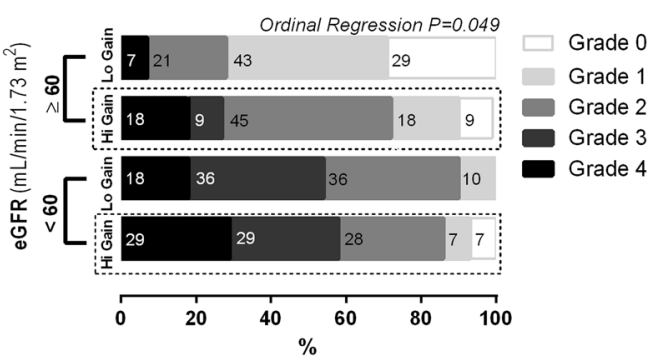

Fig. 5 Interaction between cerebral autoregulation and renal function on outcome accordingly to modified Rankin scale (a), risk of hemorrhage (b) and on severity of white matter lesions assessed at 24-h head Computed Tomography, accordingly to vanSwieten scale [33]. Subgroups were created by splitting renal function into low $\left(<60 \mathrm{~mL} / \mathrm{min} / 1.73 \mathrm{~m}^{2}\right)$ and high $\left(\geq 60 \mathrm{~mL} / \mathrm{min} / 1.73 \mathrm{~m}^{2}\right)$ estimated glomerular filtration rate (eGFR); cerebral autoregulation into low (Lo gain) and high (Hi gain) subgroups of LF gain in infarct $\left(\leq 0.90\right.$ and $\left.>0.90 \%{ }^{2} / \mathrm{mmHg}^{2}\right)$ and non-infarct hemisphere $\left(\leq 1.10\right.$ and $\left.>1.10 \%{ }^{2} / \mathrm{mmHg}^{2}\right)$. Notice that higher gain values represents worse levels of cerebral autoregulation. The interaction effect in outcome and white matter lesions was tested in multinomial logistic or ordinal regression models as appropriate

had weaker associations with outcome measures. A second possibility may be that the gain in the ischemic hemisphere is artificially lowered and cerebral autoregulation falsely normalized due to the increased vascular resistance caused by microthrombosis [47] and/or cytotoxic edema [48] in the infarcted area [49]. Clearly, much more work on the physiological determinants influencing each TFA parameter is needed.

One possible confounder on ABP variability and transfer function estimates of CA is the effect of atrial fibrillation. To address this we compared values between patients with and without atrial fibrillation and found no statistical difference between groups, suggesting atrial fibrillation did not have a significant effect on our estimates of $\mathrm{ABP}$ variability or CA.
The small sample is a limitation of this study. Also, we cannot rule out that this brain-kidney interaction is specific of a stroke population, rather than present in all individuals including healthy subjects since we don't have a control group. Other angiographic imaging modalities (CT or MRI) are more accurate in excluding significant stenosis and since we relied mainly on ultrasound exams this may be a possible limitation. ABP was assessed using non-invasive oscillometric as well as finger photoplethysmography which are known to have limitations but generally provide a relatively accurate estimate of ABP [10].

Our results show that CA assessment may be an important factor to consider in advancing treatment of acute cerebrovascular disease. Given our finding that impaired $\mathrm{CA}$ is associated with worse functional outcome, further 
work is needed to verify and explore the clinical implications of our findings. Future studies could examine CA in ischemic stroke to determine its time course. In addition, longitudinal studies examining CA in a high-risk population could shed light on a new indicator of stroke risk. Studies assessing the effect of treatments targeting those with impaired CA could determine if the poor functional outcome could be mitigated by a treatment that targets cerebral perfusion for example. Finally, longitudinal studies would also be helpful in understanding if this CA impairment is acute or a chronic condition in these stroke patients.

\section{Conclusions}

In conclusion, our findings provide support that early autoregulatory impairment of cerebral small vessels, as well as renal vessels, may be a possible mechanism linking low renal function with poor outcome of ischemic stroke. Rapid assessment of serum markers of renal dysfunction could be used as surrogates of cerebral microvascular function integrity which may help identify high-risk individuals for complications like hemorrhagic transformation and possibly provide a therapeutic target in the future.

\section{Additional file}

Additional file 1: Table S4. Relationship between Cerebral Autoregulation Transfer Function parameters (Coherence, Gain and Phase) and demographic, clinical and laboratorial variables at acute stroke (within 6 h) explorer with linear regression analysis (corrected Beta and 95\% interval of confidence intervals. Table S5. Relationship between Cerebral Autoregulation Transfer Function parameters (Coherence, Gain and Phase) and demographic, clinical and laboratorial variables at chronic stroke (3 months) explorer with linear regression analysis (corrected Beta and 95\% interval of confidence intervals. (DOCX $60 \mathrm{~kb}$ )

\section{Abbreviations}

ABP: Arterial blood pressure; CA: Cerebral autoregulation; CBFV: Cerebral blood flow velocity; CKD: Chronic kidney disease; CVRi: Cerebrovascular resistance; eGFR: Estimated glomerular filtration rate; HDL: High-density lipoprotein cholesterol; HgA1C: Glycated hemoglobin; LDL: Low-density lipoprotein cholesterol; MCA: Middle cerebral artery; mRS: modified Rankin Scale; NIHSS: National Institute of Health Stroke Scale; TFA: Transfer function analysis

\section{Funding}

This study received public national grant from Fundação para a Ciência e a Tecnologia (FCT), Portugal, PTDC/SAU-ORG/113329/2009.The funding body had no role or interference in the design of the study and collection, analysis, and interpretation of data and in writing the manuscript

\section{Availability of data and materials}

The datasets used and/or analyzed during the current study are available from the corresponding author on reasonable request.

\section{Authors' contributions}

PC Reviewed the literature, designed the study, extracted the data, analyzed the results and wrote the paper. IR Designed the study, analyzed the results, reviewed the paper. EA Designed the study, analyzed the results, and cowrote the paper. FS Reviewed the literature, designed the study, analyzed the results. JS Designed the study, analyzed the results, and co-wrote the paper and reviewed the paper. All authors read and approved the final manuscript.

\section{Ethics approval and consent to participate}

The study was conducted in Hospital Center São João, Porto, and its local ethical committee approved the study and all participants or proxy signed written informed consent.

\section{Consent for publication}

Not applicable

Competing interests

Jorge Serrador is a member of the editorial board (Associate Editor) of this journal.

\section{Publisher's Note}

Springer Nature remains neutral with regard to jurisdictional claims in published maps and institutional affiliations.

\section{Author details}

${ }^{1}$ Department Neurology, São João Hospital Center, Faculty of Medicine of University of Porto, Alameda Professor Hernani Monteiro, 4200-319 Porto, Portugal. ${ }^{2}$ Cardiovascular Autonomic Function Lab, Institute of Physiology, Faculty of Medicine of University of Lisbon, Lisbon, Portugal. ${ }^{3}$ Department of Neurology, Division of Stroke and Neurocritical, Northwestern University Feinberg School of Medicine, Chicago, IL, USA. ${ }^{4}$ Department of Pharmacology, Physiology and Neuroscience, Rutgers Biomedical Health Sciences, Newark, NJ, USA. ${ }^{5}$ Veterans Biomedical Research Institute and War Related IIIness and Injury Study Center, Department of Veterans Affairs, East Orange, USA. ${ }^{6}$ Cardiovascular Electronics, National University of Ireland Galway, Galway, Ireland.

Received: 17 August 2017 Accepted: 21 February 2018

Published online: 02 March 2018

\section{References}

1. Lee M, Saver JL, Chang KH, Liao HW, Chang SC, Ovbiagele B. Low glomerular filtration rate and risk of stroke: meta-analysis. BMJ. 2010;341:C4249.

2. Weiner DE, Tighiouart $H$, Amin MG, Stark PC, MacLeod B, Griffith JL, Salem DN, Levey AS, Sarnak MJ. Chronic kidney disease as a risk factor for cardiovascular disease and all-cause mortality: a pooled analysis of community-based studies. J Am Soc Nephrol. 2004;15(5):1307-15.

3. Kumai Y, Kamouchi M, Hata J, Ago T, Kitayama J, Nakane H, Sugimori H, Kitazono T, Investigators FSR. Proteinuria and clinical outcomes after ischemic stroke. Neurology. 2012;78(24):1909-15.

4. Naganuma M, Koga M, Shiokawa $Y$, Nakagawara J, Furui E, Kimura K, Yamagami H, Okada Y, Hasegawa Y, Kario K, et al. Reduced estimated glomerular filtration rate is associated with stroke outcome after intravenous rt-PA: the stroke acute management with urgent risk-factor assessment and improvement (SAMURAI) rt-PA registry. Cerebrovasc Dis. 2011;31(2):123-9.

5. Toyoda K, Ninomiya T. Stroke and cerebrovascular diseases in patients with chronic kidney disease. Lancet Neurol. 2014;13(8):823-33.

6. Panerai RB. Assessment of cerebral pressure autoregulation in humans-a review of measurement methods. Physiol Meas. 1998;19(3):305-38.

7. Carlstrom M, Wilcox CS, Arendshorst WJ. Renal autoregulation in health and disease. Physiol Rev. 2015;95(2):405-511.

8. Davis MJ. Perspective: physiological role(s) of the vascular myogenic response. Microcirculation. 2012;19(2):99-114.

9. Bayliss WM. On the local reactions of the arterial wall to changes of internal pressure. J Physiol. 1902:28(3):220-31.

10. Panerai RB, Rennie JM, Kelsall AW, Evans DH. Frequency-domain analysis of cerebral autoregulation from spontaneous fluctuations in arterial blood pressure. Med Biol Eng Comput. 1998;36(3):315-22.

11. Lassen NA. Cerebral blood flow and oxygen consumption in man. Physiol Rev. 1959:39(2):183-238.

12. Wardlaw JM, Doubal F, Armitage $P$, Chappell F, Carpenter T, Munoz Maniega S, Farrall A, Sudlow C, Dennis M, Dhillon B. Lacunar stroke is associated with diffuse blood-brain barrier dysfunction. Ann Neurol. 2009:65(2):194-202.

13. O'Rourke MF, Safar ME. Relationship between aortic stiffening and microvascular disease in brain and kidney: cause and logic of therapy. Hypertension. 2005;46(1):200-4. 
14. Purkayastha S, Fadar O, Mehregan A, Salat DH, Moscufo N, Meier DS, Guttmann CR, Fisher ND, Lipsitz LA, Sorond FA. Impaired cerebrovascular hemodynamics are associated with cerebral white matter damage. J Cereb Blood Flow Metab. 2014;34(2):228-34.

15. Sorond FA, Galica A, Serrador JM, Kiely DK, Iloputaife I, Cupples LA, Lipsitz LA. Cerebrovascular hemodynamics, gait, and falls in an elderly population: MOBILIZE Boston study. Neurology. 2010;74(20):1627-33.

16. Bidani AK, Griffin KA. Pathophysiology of hypertensive renal damage: implications for therapy. Hypertension. 2004;44(5):595-601.

17. Fazekas F, Kleinert R, Offenbacher H, Schmidt R, Kleinert G, Payer F, Radner $\mathrm{H}$, Lechner $\mathrm{H}$. Pathologic correlates of incidental MRI white matter signal hyperintensities. Neurology. 1993;43(9):1683-9.

18. Khatri M, Wright CB, Nickolas TL, Yoshita M, Paik MC, Kranwinkel G, Sacco RL, DeCarli C. Chronic kidney disease is associated with white matter hyperintensity volume: the northern Manhattan study (NOMAS). Stroke. 2007;38(12):3121-6.

19. Meel-van den Abeelen AS, van Beek AH, Slump CH, Panerai RB, Claassen JA Transfer function analysis for the assessment of cerebral autoregulation using spontaneous oscillations in blood pressure and cerebral blood flow. Med Eng Phys. 2014;36(5):563-75.

20. Zhang R, Zuckerman JH, Giller CA, Levine BD. Transfer function analysis of dynamic cerebral autoregulation in humans. Am J Phys. 1998;274(1 Pt 2): H233-41.

21. Nakagawa K, Serrador JM, LaRose SL, Sorond FA. Dynamic cerebral autoregulation after intracerebral hemorrhage: a case-control study. BMC Neurol. 2011;11:108

22. Castro P, Santos R, Freitas J, Rosengarten B, Panerai R, Azevedo E: Adaptation of cerebral pressure-velocity hemodynamic changes of neurovascular coupling to orthostatic challenge. Perspectives in Medicine 2012: https://doi.org/10.1016/j.permed.2012.1002.1052 [Available online 1028 March 2012]

23. Aries MJ, Elting JW, De Keyser J, Kremer BP, Vroomen PC. Cerebral autoregulation in stroke: a review of transcranial Doppler studies. Stroke. 2010;41(11):2697-704.

24. Group KDIGOKAKIW. KDIGO clinical practice guideline for acute kidney injury. Kidney International Supplements. 2012;2(1):1.

25. Levey AS, Stevens LA, Schmid CH, Zhang YL, Castro AF 3rd, Feldman HI, Kusek JW, Eggers $P$, Van Lente $F$, Greene $T$, et al. A new equation to estimate glomerular filtration rate. Ann Intern Med. 2009;150(9):604-12.

26. Castro P, Serrador J, Rocha I, Sorond F, Azevedo E. Efficacy of cerebral autoregulation in early ischemic stroke predicts smaller infarcts and better outcomes. Front Neurol. 2017;8(113)

27. Castro P, Azevedo E, Serrador J, Rocha I, Sorond F. Hemorrhagic transformation and cerebral edema in acute ischemic stroke: link to cerebral autoregulation. J Neurol Sci. 2017;372:256-61.

28. Deegan BM, Serrador JM, Nakagawa K, Jones E, Sorond FA, Olaighin G. The effect of blood pressure calibrations and transcranial Doppler signal loss on transfer function estimates of cerebral autoregulation. Med Eng Phys. 2011;33(5):553-62

29. Panerai RB. The critical closing pressure of the cerebral circulation. Med Eng Phys. 2003;25(8):621-32.

30. Aaslid R, Lindegaard KF, Sorteberg W, Nornes H. Cerebral autoregulation dynamics in humans. Stroke. 1989;20(1):45-52.

31. Serrador JM, Sorond FA, Vyas M, Gagnon M, Iloputaife ID, Lipsitz LA. Cerebral pressure-flow relations in hypertensive elderly humans: transfer gain in different frequency domains. J Appl Physiol. 2005;98(1):151-9.

32. Fiorelli M, Bastianello S, von Kummer R, del Zoppo GJ, Larrue V, Lesaffre E, Ringleb AP, Lorenzano S, Manelfe C, Bozzao L. Hemorrhagic transformation within 36 hours of a cerebral infarct: relationships with early clinical deterioration and 3-month outcome in the European cooperative acute stroke study I (ECASS I) cohort. Stroke. 1999;30(11):2280-4.

33. van Swieten JC, Hijdra A, Koudstaal PJ, van Gijn J. Grading white matter lesions on CT and MRI: a simple scale. J Neurol Neurosurg Psychiatry. 1990;53(12):1080-3

34. Curtze S, Melkas S, Sibolt G, Haapaniemi E, Mustanoja S, Putaala J, Sairanen T, Tiainen M, Tatlisumak T, Strbian D. Cerebral computed tomographygraded white matter lesions are associated with worse outcome after thrombolysis in patients with stroke. Stroke. 2015;46(6):1554-60.

35. Saeed A, DiBona GF, Grimberg E, Nguy L, Mikkelsen ML, Marcussen N, Guron $\mathrm{G}$. High- $\mathrm{NaCl}$ diet impairs dynamic renal blood flow autoregulation in rats with adenine-induced chronic renal failure. Am J Physiol Regul Integr Comp Physiol. 2014;306(6):R411-9.

36. Churchill PC, Churchill MC, Griffin KA, Picken M, Webb RC, Kurtz TW, Bidani AK. Increased genetic susceptibility to renal damage in the stroke-prone spontaneously hypertensive rat. Kidney Int. 2002;61(5):1794-800.

37. Abu-Amarah I, Bidani AK, Hacioglu R, Williamson GA, Griffin KA. Differential effects of salt on renal hemodynamics and potential pressure transmission in stroke-prone and stroke-resistant spontaneously hypertensive rats. Am J Physiol Renal Physiol. 289(2):F305-13.

38. Smeda JS, VanVliet BN, King SR. Stroke-prone spontaneously hypertensive rats lose their ability to auto-regulate cerebral blood flow prior to stroke. J Hypertens. 1999;17(12 Pt 1):1697-705.

39. Izzard AS, Graham D, Burnham MP, Heerkens EH, Dominiczak AF, Heagerty AM. Myogenic and structural properties of cerebral arteries from the strokeprone spontaneously hypertensive rat. Am J Physiol Heart Circ Physiol. 2003;285(4):H1489-94.

40. Nakamura Y, Ono H, Frohlich ED. Differential effects of T- and L-type calcium antagonists on glomerular dynamics in spontaneously hypertensive rats. Hypertension. 1999;34(2):273-8.

41. Endoh H, Honda T, Komura N, Shibue C, Watanabe I, Shimoji K. The effects of nicardipine on dynamic cerebral autoregulation in patients anesthetized with propofol and fentanyl. Anesth Analg. 2000;91(3):642-6.

42. Hamner JW, Tan CO. Relative contributions of sympathetic, cholinergic, and myogenic mechanisms to cerebral autoregulation. Stroke. 2014;45(6):1771-7.

43. Tan CO, Hamner JW, Taylor JA. The role of myogenic mechanisms in human cerebrovascular regulation. J Physiol. 2013;591(20):5095-105.

44. Tzeng YC, Chan GS, Willie CK, Ainslie PN. Determinants of human cerebral pressure-flow velocity relationships: new insights from vascular modelling and $\mathrm{ca}(2)(+)$ channel blockade. J Physiol. 2011;589(Pt 13):3263-74.

45. Simard JM, Kent TA, Chen M, Tarasov KV, Gerzanich V. Brain oedema in focal ischaemia: molecular pathophysiology and theoretical implications. Lancet Neurol. 2007;6(3):258-68.

46. Reinhard M, Neunhoeffer F, Gerds TA, Niesen WD, Buttler KJ, Timmer J, Schmidt B, Czosnyka M, Weiller C, Hetzel A. Secondary decline of cerebral autoregulation is associated with worse outcome after intracerebral hemorrhage. Intensive Care Med. 2010;36(2):264-71.

47. Wang $X$, Lo EH. Triggers and mediators of hemorrhagic transformation in cerebral ischemia. Mol Neurobiol. 2003;28(3):229-44.

48. Balami JS, Chen RL, Grunwald IQ, Buchan AM. Neurological complications of acute ischaemic stroke. Lancet Neurol. 2011;10(4):357-71.

49. Panerai RB. Cerebral autoregulation: from models to clinical applications. Cardiovasc Eng. 2008;8(1):42-59.

\section{Submit your next manuscript to BioMed Central and we will help you at every step:}

- We accept pre-submission inquiries

- Our selector tool helps you to find the most relevant journal

- We provide round the clock customer support

- Convenient online submission

- Thorough peer review

- Inclusion in PubMed and all major indexing services

- Maximum visibility for your research

Submit your manuscript at www.biomedcentral.com/submit
Biomed Central 